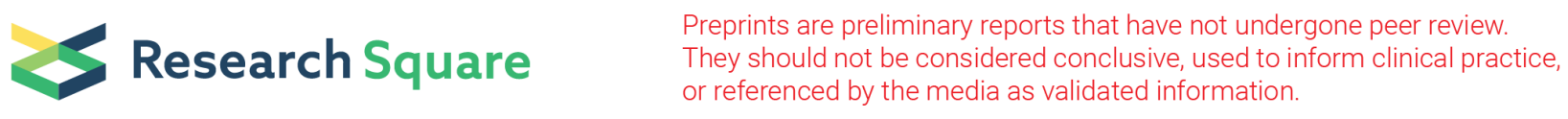

\title{
B Cell Subsets in Colombian Adults With Predominantly Antibody Deficiencies, Bronchiectasis or Recurrent Pneumonia
}

Sebastian Giraldo-Ocampo

Universidad del Valle

Anilza Bonelo Perdomo

Universidad del Valle

Andrés Felipe Zea-Vera ( $\sim$ andres.zea@correounivalle.edu.co )

Universidad del Valle https://orcid.org/0000-0001-9127-3677

\section{Research Article}

Keywords: B cell subsets, predominantly antibody deficiencies, CVID, bronchiectasis, recurrent pneumonia, Colombia

Posted Date: November 1st, 2021

DOI: https://doi.org/10.21203/rs.3.rs-997560/v1

License: (c) (i) This work is licensed under a Creative Commons Attribution 4.0 International License. Read Full License 


\section{Abstract \\ Purpose.}

To evaluate lymphocyte's populations and B cell subsets in patients presenting with PAD diagnosed with bronchiectasis or recurrent pneumonia seen in Cali (Colombian Southwest region).

\section{Methods.}

16 patients with PAD, 20 with bronchiectasis or recurrent pneumonia and 20 healthy controls were included. Lymphocyte populations (T, B \& NK cells) and B cell subsets were evaluated in Peripheral Blood mononuclear cells (PBMC) using flow cytometry, using the T/B/NK reagent and the pre-germinal center antibody panel proposed by the EUROflow consortium, respectively. Clinical and sociodemographic data was collected (hospital records and interview). EUROclass and the classification proposed by Driessen et al were implemented.

\section{Results.}

B cell subsets were disturbed when compared to the age range matched healthy donors. Among B cell subsets,memory $B$ cellcompartment was the most affected, especially switched memory B cells. Four participants were classified as B- and two CVID as smB-Trnorm and smB-21lo groups according to EUROclass classification. The most frequent pattern proposed by Driessen et al were B-cell production and germinal center defect. PAD participants also showed alteration in the B cell subsets correlation. Non-PAD participants with pulmonary complication also had alteration in B cell subsets.

\section{Introduction}

Predominantly Antibody Deficiencies (PAD) are the most prevalent group of the ten categories of inborn errors of immunity currently recognized by the International Union of Immunological Societies, comprising about half of these disorders[1, 2]. Among PAD, Common variable immunodeficiency (CVID), selective IgA deficiency (SIgAD) and agammaglobulinemia are the most representative disorders, although other disorders are recognized as PAD, such as selective IgM deficiency (SIgMD) and specific antibody deficiency[3,4]. Frequently, patients with PAD, especially with CVID, have an unusual susceptibility to sinopulmonary infections, commonly by encapsulated bacteria, leading to recurrent pneumonia[5]. The recurrent infections may cause different pulmonary complications, being bronchiectasis the most prevalent in PAD, with a mean of $34 \%$ in CVID patients[6]. In turn, the vicious cycle of inflammation and infection of bronchiectasis could contribute to the disturbance of the humoral immune response and therefore to infection susceptibility[7].

The diagnosis criteria for PAD disorders are well stablished by the European Society for Immunodeficiencies (ESID) and are based on serum immunoglobulin levels, responses against vaccine antigens and no profound alterations in T cell compartment along with increased susceptibility to infections, autoimmunity, lymphoproliferation, granulomas and/or history of affected family members[8]. Due to alterations in the humoral adaptative immune response in PAD patients, the evaluation of B cell subsets could provide relevant information for the characterization of each patient and some clues about the physio pathological mechanism of the disease[9]. Accordingly, three classification systems have been proposed, based on B cell subsets, that allocate CVID patients in homogeneous groups: Freiburg, Paris and Euroclass[10-12]. The group in which a patient is allocated can be associated with certain complications such as autoimmunity, lymphoproliferation or splenomegaly. Among the three classification systems, Euroclass is the one with more B cell subsets and groups incorporated and allow discrimination of CVID patients with non-infectious complications similar to Freiburg and Paris[12]. A fourth classification system was proposed by Driessen et al.[13], in which each patient is allocated in one of five B-cell patterns reflecting each one a different pathophysiology of the disease.

Currently, published data about immunological assessment in subjects diagnosed with PAD is limited in Colombia. The few studies available were published by the primary immunodeficiency group from Universidad de Antioquia[14]. For this reason, the aim of this study was to evaluate the lymphocyte populations and $B$ cell subsets in patients seen in Cali, who came from different locations from the Colombian Southwest region.

\section{Methods}

\section{Study Subjects}

This is a prospective, observational cohort study (non-interventional). We enrolled 56 participants: 16 patients with Predominantly Antibody Deficiencies (PAD) and NCFBQ or recurrent pneumonia, 20 patients with NCFBQ or recurrent pneumonia (without humoral deficiencies) and 20 gender-age matched healthy controls.

All cases were referred to the Clinical Immunology Clinic at Universidad del Valle (Cali, Colombia) by pulmonologists, internists or allergists attending patients from the southwest of Colombia (Valle, Cauca and Nariño departments) in different medical centers in Calio from January 2nd 2019 to March 31 st, 2020.

Patients fulfilling the inclusion criteria: aged $\geq 14$ and $<65$ years with bronchiectasis on chest computed tomography (CT) and the clinical syndrome of bronchiectasis (cough, sputum production, or recurrent respiratory infections) or with recurrent pneumonia (at least 2 pneumonias in 1 year or more than 3 pneumonias throughout life, with radiographic resolution between episodes) and not the exclusion criteria as inability to give informed consent, bronchiectasis due to cystic fibrosis, and traction bronchiectasis associated with interstitial lung disease or another respiratory disorder, acquired immune defects or secondary immunodeficiencies (chronic myeloid leukemia, multiple myeloma, Human Immunodeficiency Virus HIV infection, immunosuppression secondary 
to drugs) were enrolled. Inborn errors of immunity were defined according with ESID classification and diagnostic criteria. Peripheral blood sampes anticoagulated with EDTA and clinical data were collected and store according with IRB protocols.

The Inborn Error of Immunity diagnosis was corroborated by the physician from the study (Clinical Immunologist). In case of discrepancy, a third physician were contacted. PAD were defined according to the ESID criteria[8], bronchiectasis according to the British Thoracic Society guideline for non-CF bronchiectasis[15] and recurrent pneumonia as two episodes of pneumonia in one year or three in the lifetime with radiography resolution between episodes[16].

The study was approved by the Institutional committee of Human Ethical review of the Universidad del Valle, ID: 010-019R and by the ethics committee of Hospital Universitario del Valle "Evaristo Garcia”, ID: 050-2019. Informed consent was obtained from the all the patients and healthy donors. This study was performed in line with the principles of the Declaration of Helsinki.

\section{Isolation of Peripheral Blood Mononuclear Cells (PBMC) and leucocytes evaluation}

PBMCs were isolated by density gradient centrifugation using Ficoll-Paque (Sigma-Aldrich). Briefly, total blood was diluted in $10 \mathrm{~mL}$ of RPMI 1640 and centrifuged at 1200 RPM with $3 \mathrm{~mL}$ of Ficoll-Paque. The upper layer containing the plasma was removed and the PMBC fraction transferred into a new $15 \mathrm{~mL}$ tube and washed twice with $10 \mathrm{~mL}$ RPMI 1640 . Cell viability and counting was performed using trypan blue staining. PBMC were cryopreserved in liquid nitrogen in freezing medium (40\% Fetal Bovine Serum (FBS)/10\% DMSO) until the analysis. 500uL of blood were used for evaluation of white blood cells by hemogram analysis.

PBMC were thawed in a water bath at $37^{\circ} \mathrm{C}$ and then FBS were add drop by drop, then the cells were transferred to a sterile $15 \mathrm{~mL}$ Falcon, wash twice with 10 $\mathrm{mL}$ of RPMI, $10 \%$ FBS and centrifuged at 1200 RPMI for 10 min. Finally, the cellular pellet was reconstituted with $2 \mathrm{~mL}$ of FACS Buffer (PBS 1 X, $10 \mathrm{mM}$ EDTA and $5 \%$ FBS). Cell Viability and count were performed as described above. Only samples with a viability index greater than $80 \%$ were evaluated.

\section{Flow cytometric analysis}

The evaluation of lymphocytes populations was performed using $10 \mu \mathrm{L}$ of the 6-Color TBNK reactive from Becton Dickinson (BD) in a final volume of $60 \mu \mathrm{L}$. $2.5 \times 10^{5}$ cells were stained and incubated for 15 minutes at room temperature at then all the events were acquired in the cytometer. The identification of the populations was as follow: $\mathrm{CD} 4^{+} \mathrm{T}$ cells $\left(\mathrm{CD} 45^{+} \mathrm{CD} 3^{+} \mathrm{CD} 4^{+}\right), \mathrm{CD} 8^{+} \mathrm{T}$ cells $\left(\mathrm{CD} 45^{+} \mathrm{CD} 3^{+} \mathrm{CD} 8^{+}\right)$, double negative $\mathrm{T}$ cells $\left(\mathrm{CD} 45^{+} \mathrm{CD} 3^{+} \mathrm{CD} 4^{-} \mathrm{CD} 8^{-}\right)$, double positive T cells $\left(\mathrm{CD} 45^{+} \mathrm{CD}^{+} \mathrm{CD} 4^{+} \mathrm{CD} 8^{+}\right)$, B cells $\left(\mathrm{CD} 45^{+} \mathrm{CD} 3^{-} \mathrm{CD} 19^{+}\right)$and NK cells $\left(\mathrm{CD} 45^{+} \mathrm{CD} 3^{-}(\mathrm{CD} 16-\mathrm{CD} 56)^{+}\right)$.

Immunophenotyping of B cell subsets was performed in PBMCs using the pre-germinal center (pre-GC) antibody panel proposed by the EuroFlow Consortium [17]: CD19- PECy7 (clone J3-119) from Beckman Coulter; CD5-PE (clone UCHT-2), SmlgD-PerCPCy5.5 (clone IA6-2) and SmlgM-BV510 (clone MHM-88) from Biolegend; CD21-APC (clone B-ly4), CD27-BV421 (clone M-T271) and CD38-HB7 from BD Biosciences. The antibody volume was 2.5; 2.5; 0.75; $0.65 ; 5 ; 0.5$ and $2.5 \mu \mathrm{L}$, respectively, in a final volume of $100 \mu \mathrm{L}$. The cells were incubated for 30 minutes at room temperature at then the antibodies in supernatant were washed with FACS buffer. A minimum of $7.5 \times 10^{5}$ events/leukocytes were acquired per tube. CompBeads Set Anti-Mouse Ig, K (BD bioscience) was used for fluorescence compensation.

Based on the staining pattern of the mentioned above antibodies and the side (SSC) and forward scatter (FSC) parameters, B cells (CD19 ${ }^{+}$SSClow $\mathrm{FSC}^{\text {low }}$ lymphocytes) were classified into immature/transitional B lymphocytes $\left(\mathrm{CD}^{+} \mathrm{CD} 27^{-} \mathrm{CD}^{2} 8^{++} \mathrm{smlgM}^{++} \mathrm{smlgD}^{+}\right)$; naïve $\mathrm{CD}^{+}$

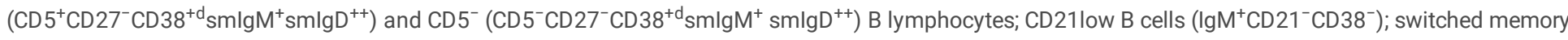

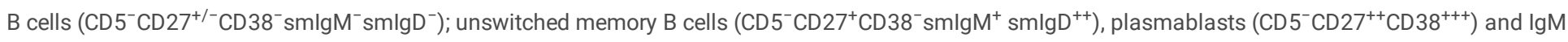
only memory cells $\left(\mathrm{CD}^{-} \operatorname{lgM} \mathrm{M}^{+} \operatorname{lgD}-\mathrm{CD} 27^{+}\right.$) (figure 1). B cell subsets were also identified using the IgD vs CD27 approach for the classification of patients according to EUROclass[12].

A negative control (unstained cells) was included for each sample. All assays were performed in FACSCanto ${ }^{\mathrm{TW}}$ II cytometer using FACSDiva (BD) software. Data analysis was performed with Flowjo VX.0. and absolute frequencies were calculated by dual-platform approach. Decrease or increase in the B cell subsets was defined as a value below the minimum value divide by 1.5 or above the maximum value multiplied by 1.5 of the corresponding age range: $14-29$, 30-39, 40-50 and more than 50 years old. This approach was used due to the non-normality of data and to detect an important quantitative alteration in the $B$ cell subset evaluated.

PAD participants were classified according to EUROclass[12] and Driessen et al[13]. The former defines the following groups: B-, SmB- and SmB+, smB+21norm, smB+21lo, smB-Trnorm, smB-Trhi, smB-21lo and smB-21norm after evaluation of B cells, switched memory B cells, transitional B cells and CD21low B cells. Driessen et al defined five patterns: 1. B-cell production and germinal center defect, 2. Early peripheral B-cell maturation or survival defect, 3. B-cell activation and proliferation defect, 4. Germinal center defect, 5. Post germinal center defect.

\section{Statistical analysis}

Statistical analysis was performed with R programing language in RStudio software. Mann-Whitney and Kruskal Wallis tests were used to compared groups with continuous outcomes. Spearman correlation was used to evaluate the correlation between B cell subsets. Fisher exact test was used for categorical variables. 2-sided $\mathrm{p}<0.05$ was used to define statistical significance.

\section{Results}

\section{Subjects Characteristics}


The study included 56 participants: In which 16 with PAD, 20 with bronchiectasis or recurrent pneumonia and 20 healthy donors. The group with PAD included nine CVID patients, four with SIgAD, one of them with IgG2 and IgG4 deficiency, two with SIgMD and one with IgG non-specified Hypogammaglobulinemia (HipoNE). The group with respiratory complications alone had six subjects with bronchiectasis, seven with recurrent pneumonia and seven with both conditions. The median age for PAD, respiratory complications alone and healthy donors' group were 35 (IQR: 24-52), 39 (IQR: 29-54) and 36 (IQR: 28-42) years old, respectively with no difference between groups $(p$-value $=0.99)$ ). The proportions of males and females were similar $(p$ value $=0.8)$ between groups and predominantly of mestizo ethnicity. The sociodemographic information as well as data about exposition to biomass, wood smoke and tobacco is depicted in Table 1. Among PAD, the 15 years old patient with HipoNE and CVID patients with 30 (IQR: 23-36) years old had the lower median of age and the two patients with SIgMD had the highest age, both subjects with 64 years old. The median delay in the PAD diagnosis was 11 (IQR: 6-16) years. The etiology of the bronchiectasis and/or recurrent pneumonia of the participants with pulmonary complications without inborn errors of immunity were predominantly postinfectious (55\%). Other etiologies included asthma, primary ciliary dyskinesia, gastroesophageal reflux, idiopathic and one case with autoimmunity. One participant with recurrent pneumonia were excluded from the analysis due to myeloma diagnosis after the inclusion in the study.

Table 1

Sociodemographic data of the participants

\begin{tabular}{|c|c|c|c|c|c|}
\hline Parameter & PAD & $\mathrm{BQ}$ & NR & $B Q+N R$ & HD \\
\hline $\mathrm{n}$ & 16 & 6 & 7 & 7 & 20 \\
\hline \multicolumn{6}{|l|}{ Age, $n(\%)$} \\
\hline $15-29$ & $5(31)$ & $1(17)$ & $2(29)$ & $3(43)$ & $7(35)$ \\
\hline $30-39$ & $5(31)$ & 2(33) & $2(29)$ & $1(14)$ & $6(30)$ \\
\hline $40-50$ & $2(13)$ & $1(17)$ & $1(14)$ & 0 & $5(25)$ \\
\hline$>50$ & $4(25)$ & $2(33)$ & $2(29)$ & $3(43)$ & $2(10)$ \\
\hline \multicolumn{6}{|l|}{ Gender, n(\%) } \\
\hline Male & $8(50)$ & $3(50)$ & $4(57)$ & $2(29)$ & $8(40)$ \\
\hline Female & $8(50)$ & $3(50)$ & $3(43)$ & $5(71)$ & $12(60)$ \\
\hline \multicolumn{6}{|l|}{ Ethnicity, n(\%) } \\
\hline Mestizo & $12(75)$ & $3(50)$ & $6(86)$ & $6(86)$ & $17(85)$ \\
\hline Black & $4(25)$ & $2(33)$ & $1(14)$ & $1(14)$ & $1(5)$ \\
\hline Indigenous & 0 & $1(17)$ & 0 & 0 & 0 \\
\hline White & 0 & 0 & 0 & 0 & $2(10)$ \\
\hline Bronchiectasis, $\mathrm{n}(\%)$ & $1(6)$ & $6(100)$ & - & - & - \\
\hline R. pneumonia, n(\%) & $6(38)$ & - & $7(100)$ & - & - \\
\hline Bronchiectasis and R.pneumonia, $\mathrm{n}(\%)$ & $9(56)$ & - & - & $7(100)$ & - \\
\hline \multicolumn{6}{|l|}{ Exposure to biomass, $n(\%)$} \\
\hline Yes & $3(19)$ & $1(17)$ & $2(29)$ & $1(14)$ & - \\
\hline No & $13(81)$ & $5(83)$ & $5(71)$ & $6(86)$ & - \\
\hline \multicolumn{6}{|l|}{ Exposure to wood smoke, $n(\%)$} \\
\hline Yes & $1(6)$ & $4(67)$ & $1(14)$ & 2029 & - \\
\hline No & $15(94)$ & $2(33)$ & $6(86)$ & $5(71)$ & - \\
\hline \multicolumn{6}{|l|}{ Exposure to tobacco smoke, n(\%) } \\
\hline Yes & $6(38)$ & $3(50)$ & $2(29)$ & $1(14)$ & - \\
\hline No & $10(62)$ & $3(50)$ & $5(71)$ & $6(86)$ & - \\
\hline
\end{tabular}

Out of the 16 patients with PAD, nine (56\%) had bronchiectasis and recurrent pneumonia (six CVID, two SIgAD and one SIgMD), six (38\%) had only recurrent pneumonia (three CVID, the one with non-specified reduction in IgG, one SIgAD and SIgMD) and only one participant, with SIgAD, had only bronchiectasis.

\section{Peripheral blood lymphocyte populations}

The median of lymphocyte counts was higher in the PAD group when compared with the healthy donors ( $p$-value $<0.05)$ and similar to those with both pulmonary complications ( $p>0.05$ ). The median of T cells (although no statical significance, $p=0.06)$ and particularly CD8+ T cells $(p<0.05)$ were higher in CVID when compared with all the other groups. The median of NK cells of PAD patients, along with subjects with recurrent pneumonia, were lower, although there was no statistical significance. When the PAD disorders are analyzed, CVID and SIgMD have the highest median of lymphocytes and T cells. However, CD8+ T cells median are higher in CVID while CD4+ T cells median is higher in SlgMD. CD4:CD8 proportion is reduced in CVID (median = 0.8) and increase in 
SIgMD (median = 3.3) (figure 2). NK cells were reduced in CVID patients as well as those with only recurrent pneumonia. CVID participants also have the highest median for double negatives T cells (177 cells $/ \mu \mathrm{L}$ vs $<100$ cells $/ \mu \mathrm{L}$ in the other groups).

\section{B cell subsets}

Relative frequency of PAD subjects B cell with bronchiectasis and recurrent pneumonia were lower when compared with PAD with only recurrent pneumonia (median: 3.5 vs 10.5, respectively). Among B cell subsets, switched memory B cells tend to be lower in PAD with both pulmonary conditions when compared with those with only recurrent pneumonia (median: 1.3 vs 3.9, respectively) as well as plasmablast (median: 0.02 vs 0.08 ) (figure $3 a$ ). Regarding absolute frequency, participants with the three conditions had lower median of B cells, CD5- naïve B cells, total memory B cells, unswitched memory B cells and plasmablasts. On the other side, participants with bronchiectasis and recurrent pneumonia without PAD, when compared to the healthy donors, had higher transitional B cells and lower switched memory cells relative frequency median; and those with recurrent pneumonia also had lower relative and absolute median of B cells and higher median of relative and absolute frequency of plasmablasts when compared to healthy donors (Figure 3a).

When PAD disorders were analyzed, CVID participants had lower relative frequency median of B cells, total memory, switched memory and plasmablasts when compared with the healthy donors. Also, participants with SIgAD had lower median of switched memory cells and plasmablast and SlgMD had the highest median of switched memory, total memory and plasmablast when compared with the other groups (Figure $3 b$ ). A similar result was obtained when analyzing the $B$ cell subsets absolute frequency, although in both scenarios, there was no statistical significance.

Correlation analysis among B cell subsets in healthy donor and PAD group reveal a loss of correlation between several of this populations in the latter group (figure 4). Furthermore, in healthy donors, total memory cells are weakly correlated with switched and unswitched memory B cells, IgMonly B cells, plasmablast and CD21low B cells (figure 4a). On the other hand, in PAD group there is a strong inverse correlation between switched memory B cells and CD21 low B cells and a weekly positive correlation between transitional and CD21low B cells (Figure 4b), while in healthy donors this correlation is inverted.

\section{Alteration of B cell subsets frequencies and classification of PAD participants}

Four participants with CVID had less than $1 \%$ B cells and therefore, most of their absolute count of B cell subsets were reduced when compared to the age range-matched healthy donor. The other five CVID subjects, three had reduction in total memory $\mathrm{B}$ cells, two had reduction in both switched and unswitched memory B cells, two only in switched memory B cells and the last one had normal levels of these B cell subsets (Table 2). Three out of these five CVID patients also had an increase in CD21low B cells absolute frequency and only one had reduction in plasmablasts absolute count. Out of the four patients with SIgAD, two had reduction in switched and unswitched memory B cells, one had reduction only in switched memory and the other one had an increase in unswitched memory B cells. The two participants with SlgMD had increased relative and/or absolute frequencies of total memory B cells, switched and unswitched memory B cells. Only one PAD participants had alteration in naïve CD5- B cells and three (one SIgAD and the two with SlgMD) had reduction in CD5+ naïve B cells. The four CVID participants with less than $1 \%$ B cells were classified into the B-EUROclass group and three of them in pattern 1 (B-cell production and germinal center defect) of Driessen et al classification. Three CVID participants were classified as smB+21norm and two in smB- group. Three patients were classified as pattern 3 (B-cell activation and proliferation defect), 4 (Germinal center defect) and 5 (Post germinal center defect), respectively (Table 2). 
Table 2

B cell subsets frequency and classification of PAD participants. Absolute frequency is shown between parentl

\begin{tabular}{|c|c|c|c|c|c|c|c|c|c|c|c|}
\hline Group & Age(years) & $\begin{array}{l}\text { Dx } \\
\text { Delay } \\
\text { (years) }\end{array}$ & $\begin{array}{l}\text { Pneumonia } \\
\text { episodes }\end{array}$ & $\begin{array}{l}\text { lg } \\
\text { treatment }\end{array}$ & $\begin{array}{l}\text { Other } \\
\text { manifestations } \\
\text { diagnosed }\end{array}$ & CD4:CD8 & B cells & $\begin{array}{l}\text { Total } \\
\text { memory B } \\
\text { cells }\end{array}$ & sM B cells & $\begin{array}{l}\text { UsM B } \\
\text { cells }\end{array}$ & $\begin{array}{l}\text { Nai' } \\
\text { B cr }\end{array}$ \\
\hline \multicolumn{12}{|l|}{ PAD } \\
\hline CVID-1 & 56 & 11 & 3 & Yes & Skin abscesses & 0.4 & $<1^{*}$ & $0.5^{\star}$ & $0.1^{\star}$ & $0.21^{*}$ & $15^{\star}$ \\
\hline CVID-2 & 30 & 2 & $>5$ & Yes & Viral Hepatitis & 0.6 & $12(430.8)$ & $8(34.4)$ & $1.3(5.7)^{*}$ & $\begin{array}{l}9.5 \\
(40.8) *+\end{array}$ & $\begin{array}{l}58 . c \\
(25:\end{array}$ \\
\hline CVID-3 & 31 & 14 & $>10$ & No & sinusitis & 8 & $<1(2.9) *+$ & $38(1.1) \dagger$ & $\begin{array}{l}23.5 \\
(0.7) \dagger\end{array}$ & $1.1(0) *+$ & $29 . i$ \\
\hline CVID-4 & 37 & 6 & 3 & Yes & - & 0.5 & $3.5(90.2)^{\star}$ & $\begin{array}{l}15.7 \\
(14.2) \dagger\end{array}$ & $\begin{array}{l}0.11 \\
(0.1) *+\end{array}$ & $\begin{array}{l}15.7 \\
(14.2)\end{array}$ & $49 . i$ \\
\hline CVID-5 & 23 & 6 & $>3$ & Yes & Otitis, sinusitis & 0.3 & $\begin{array}{l}2.7 \\
(77.5) *+\end{array}$ & $\begin{array}{l}19.5 \\
(15.1) \dagger\end{array}$ & $\begin{array}{l}3.4 \\
(2.7) *+\end{array}$ & $\begin{array}{l}12.1 \\
(9.4) \dagger\end{array}$ & $49 . !$ \\
\hline CVID-6 & 24 & 11 & 2 & Yes & $\begin{array}{l}\text { Diarrhea, ITP, AD, } \\
\text { Sjögren } \\
\text { syndrome }\end{array}$ & 0.8 & $\begin{array}{l}17.4 \\
(819.5)\end{array}$ & $\begin{array}{l}5.09 \\
(41.7) \star\end{array}$ & $\begin{array}{l}0.5 \\
(4.2) * t\end{array}$ & $\begin{array}{l}6.7 \\
(54.7)\end{array}$ & $\begin{array}{l}42.4 \\
(34:\end{array}$ \\
\hline CVID-7 & 16 & 6 & 6 & Yes & - & 1.4 & $<1(0.2) *+$ & $\begin{array}{l}35.8 \\
(0.1) \dagger\end{array}$ & $0(0) * \dagger$ & $0(0) *+$ & 2.6 \\
\hline CVID-8 & 36 & 9 & $>10$ & Yes & $\begin{array}{l}\text { Kernicterus, } \\
\text { Hypoacousis, } \\
\text { otitis, asthma, } \\
\text { gastritis, AD }\end{array}$ & 1.9 & $14(380.8)$ & $\begin{array}{l}14.9 \\
(56.7)\end{array}$ & $7.6(28.8)$ & $\begin{array}{l}5.1 \\
(19.5)\end{array}$ & $\begin{array}{l}60.1 \\
(22 \imath\end{array}$ \\
\hline CVID-9 & 21 & 2 & $>5$ & Yes & $\begin{array}{l}\text { Sinusitis, } \\
\text { nephrotic } \\
\text { syndrome, } \\
\text { gastroesophageal } \\
\text { reflux }\end{array}$ & 0.8 & $<1(4.3) *+$ & $0.1(0) *+$ & $0.05(0) *+$ & $0(0) *+$ & $0(0$ \\
\hline $\begin{array}{l}\text { SlgAD- } \\
1\end{array}$ & 34 & 17 & $>10$ & Yes & $\begin{array}{l}\text { Esophageal } \\
\text { candidiasis }\end{array}$ & 1.1 & $9.3(189.8)$ & $\begin{array}{l}1.18 \\
(2.2)^{\star}+\end{array}$ & $\begin{array}{l}0.09 \\
(0.2) *+\end{array}$ & $\begin{array}{l}2.8 \\
(5.2) *+\end{array}$ & 59.6 \\
\hline $\begin{array}{l}\text { SlgAD- } \\
2\end{array}$ & 63 & 28 & $>10$ & No & Gastritis, asthma & 2.1 & $\begin{array}{l}13.1 \\
(305.2)\end{array}$ & $\begin{array}{l}19.6 \\
(59.8)\end{array}$ & $\begin{array}{l}14.2 \\
(43.3)\end{array}$ & $\begin{array}{l}4.1 \\
(12.4) \sim\end{array}$ & $46 . \varepsilon$ \\
\hline $\begin{array}{l}\text { SlgAD- } \\
3\end{array}$ & 50 & 5 & 0 & No & Gastritis, asthma & 0.8 & $\begin{array}{l}11.3 \\
(340.1)\end{array}$ & $\begin{array}{l}8.6 \\
(29.4) *+\end{array}$ & $3.8(13) *+$ & $2(6.8) *+$ & $\begin{array}{l}70.6 \\
(70 .\end{array}$ \\
\hline $\begin{array}{l}\text { SlgAD- } \\
4\end{array}$ & 48 & 15 & 3 & No & $\begin{array}{l}\text { Gastritis, asthma, } \\
\text { sinusitis }\end{array}$ & 1.9 & $10.9(170)$ & $19(32.3) \dagger$ & $\begin{array}{l}3.2 \\
(5.4) *+\end{array}$ & $\begin{array}{l}15.7 \\
(26.7)\end{array}$ & 59.1 \\
\hline $\begin{array}{l}\text { SlgMD- } \\
1\end{array}$ & 64 & 28 & 4 & No & $\begin{array}{l}\text { Asthma, } \\
\text { hypothyroidism }\end{array}$ & 4.7 & $10(214)$ & $\begin{array}{l}27.9 \\
(59.7)\end{array}$ & $\begin{array}{l}24.5 \\
(52.4)\end{array}$ & $\begin{array}{l}5.3 \\
(11.3) \sim ~\end{array}$ & 40. \\
\hline $\begin{array}{l}\text { SlgMD- } \\
2\end{array}$ & 64 & 57 & 4 & No & Asthma & 1.9 & $\begin{array}{l}4.6 \\
(176.3)^{\star}\end{array}$ & $\begin{array}{l}44.5 \\
(78.5) \sim\end{array}$ & $\begin{array}{l}36.2 \\
(63.8) \sim\end{array}$ & $\begin{array}{l}3.8 \\
(6.6) \sim\end{array}$ & $\begin{array}{l}30.2 \\
(53 .\end{array}$ \\
\hline HipoNE & 15 & 13 & $>15$ & No & $\begin{array}{l}\text { Asthma, sinusitis, } \\
A D \text {, absent corpus } \\
\text { callosum }\end{array}$ & 2.3 & $7.6(175.7)$ & $\begin{array}{l}16.4 \\
(28.8) \dagger\end{array}$ & $4.6(8) *+$ & $\begin{array}{l}6.9 \\
(12.1)+\end{array}$ & 43.1 \\
\hline $\mathrm{HD}$ & $36(28-42)$ & - & - & - & - & 2.1 & $14(290)$ & $27.7(72.2)$ & $15.5(43)$ & $9.9(21.7)$ & $35 . \varsigma$ \\
\hline BQRN & $46(32-55)$ & - & 5 & - & - & 1.8 & $9.2(242)$ & $16.2(32.7)$ & 7.9(19) & $6.7(15.3)$ & $53\left(^{\circ}\right.$ \\
\hline RN & $38(31-47)$ & - & 3 & - & - & 1.7 & $6.3(168.9)$ & $23.8(50.4)$ & $13.2(26.6)$ & 7.4(18.9) & 49.2 \\
\hline $\mathrm{BQ}$ & $36(31-51)$ & - & 0 & - & - & 2.1 & $12.9(184.9)$ & $21.6(22.1)$ & $14.8(14.1)$ & $5.2(9.1)$ & 47.2 \\
\hline
\end{tabular}

AD: Atopic dermatitis; BQ: bronchiectasis; BQRN: BQ and RN; ITP: Immune Thrombocytopenic Purpura; RN: recurrent pneumonia. *Reduction in relative frequধ relative frequency; Increased relative and absolute frequency

Finally, participants in the groups of pulmonary complication without inborn errors of immunity also had reduction in B cell subsets when compared to age range-matched healthy donor either in relative or absolute frequency or both, especially in the memory B cell compartment. Out of the six participants with only bronchiectasis, three had reduction in transitional B cells, four in switched memory B cells, two had increase memory unswitched memory B cells and three in total memory B cells. Among the six subjects with recurrent pneumonia, two had reduction in CD5- naïve B cell subsets, four in transitional B cells, three in switched memory B cells, four in unswitched memory B cells and two had increased plasmablasts. Out of the seven patients with both conditions, three had reduction in switched memory B cells, two had increased unswitched memory cells and two had increased CD21low B cells.

\section{Discussion}


Predominantly antibody deficiencies are one of the most complex disorders among Inborn Errors of Immunity, with common variable immunodeficiency (CVID), a highly heterogenous and with largely unknown etiology, being the most complex PAD disorder. This study evaluated the peripheral blood lymphocytes population and B cell subsets, which have proven to be useful in the classification of PAD[12] patients and as a first approximation to the probable physiopathology mechanism of the disorder[9, 13].

Analysis of blood lymphocytes showed an increasement in lymphocytes absolute counts, T cells and particularly CD8+ T cells in CVID participants, which was reflected in the CD4:CD8 ratio below the normal value in PAD participants (Table 2). CVID patients also had lower median of NK cells and increased double negative (CD4-CD8-) T cells when compared to health donors. Total memory, switched and unswitched memory B cells were the subsets most frequently altered in PAD. We also found an alteration in the correlation between B cell subsets (figure 4), suggesting that alterations in these subpopulations also affect how they correlate with each other.

Experimental Data has revealed disturbance in the T cells compartment in CVID patients, however, data is still limited. Reduction in CD4+ T cells and expansion of $C D 8+T$ cells with a senescence phenotype has been found that alter the CD4:CD8 ratio but without the common presentation of $T$ cell alterations such as viral and fungal opportunistic infections $[18,19]$. Similar to the reported, CVID participants in this study showed alterations in T cell compartment, however CD4+ T cells absolute counts were normal but CD8+ T cells were significantly increased, disturbing the CD4:CD8 ratio, increased double negative T cells and NK cells. SIgAD patients do not showed any significance alteration in this compartment and SIgMD participants had increased CD4+ T cells, suggesting that CVID, but also non-CVID PAD patients had alterations in T and NK cell compartment, however, a more precise immunophenotyping is needed to identified T cell and NK cell subsets alterations.

Alteration in B cell subsets has been recognized to be present in PAD patients, although CVID patients are the more widely studied[9, 14, 20, 21]. It was found that the most frequently altered B cell subsets in PAD participants were the B memory compartment, especially Switched memory B cells, and plasmablasts, even in non-CVID PAD patients, when compared to the median of healthy donors (figure 3 ) and to the age range-matched healthy donors (Table 2), indicating that this subsets are the most frequently altered as previously reported in Colombian CVID patients[14], however, no participant showed alterations neither in the frequency of Naïve CD5+ (also known as pre-naïve B cells) that had been associated with autoimmunity[22] nor the naïve CD5- B cells, as reported in a high percentage in the Colombian CVID patients mentioned above, and 4/9 patients showed less than $1 \%$ B cells, suggesting a different alterations in B cell subsets between these two geographical areas of Colombia, although the comparison has to be taken with precautious as different markers and gating strategy were used for the identification of B cell subsets. Furthermore, one CVD patient had no reduction in switched or unswitched memory B cells, which implies a different alteration pattern.

Accordingly, classification of EUROclass of this patient did not classified it in a group associated with non-infectious complications and the classification of Driessen et al[13] classified it in the pattern of Post germinal center defect, although most of CVID participants were classified as pattern 1 (B-cell production and germinal center defect) and pattern 3 (B-cell activation and proliferation defect). SIgAD participants showed similar alterations to CVID individuals, implying a possible similar pathological mechanism, two out of the four participants had B-cell activation and proliferation defect. On the other hand, SIgMD showed increased numbers of switched memory B cells and plasmablasts, implying a possible skewness toward isotype-switched phenotypes, at least in the two patients analyzed. This finding highly the importance of B cell subsets analysis in PAD patients, as they are a heterogeneous population.

PAD patients, as showed here, also has alterations in B cell subsets correlation, which further implies a complex alteration in these disorders. The most striking being the loss of correlation between switched memory B cells with all other cells and a positive correlation between transitional B cells and CD21low B cells, which suggest that the more numbers of transitional B cells, the more numbers of CD21low B cells and a negative correlation between switched memory $B$ cells and CD21 low B cells, implying that the more profound the alteration in this memory B cells, the higher the frequency of CD21low B cells.

Euroclass and Driesse et al classifications are important because can potentially modified how the patients are monitored longitudinally in time, with smBTrnorm and smB-21norm being the patients with most probability to develop any non-infectious complication such as granulomas, autoimmunity and lymphoproliferation[12] but also are important as a started point to further studies about the precise determination of the molecular altered mechanism/s in these patients, which would provide information for the understanding of the disease and the development of better treatments[23].

Finally, it was also found disturbance in B cell subsets in the non-PAD participants with bronchiectasis, recurrent pneumonia or both conditions as well as reduction in NK cells in recurrent pneumonia group. A previous study reported that non-PAD bronchiectasis patients have quantitative alterations in $B$ cells, CD4+ T cells, IgG3 and neutrophil respiratory burst[24]. We showed here that patients with this pulmonary disease also have alteration in B cell subsets, although it is not possible to determine whether this disturbance contribute to the bronchiectasis development or the bronchiectasis itself lead to the B cell compartment alterations. Adults with recurrent pneumonia are less studied, but analysis of the six patients revealed alterations in the B cell subpopulations as well. Further studies are required to precisely determine whether the alterations in immune function of patients with these pulmonary diseases is significantly contributing to the clinical phenotype.

In conclusion, PAD participants showed alterations in lymphocytes populations and B cell subsets, as well as disturbance in the correlation of these B cells subpopulations, especially in switched memory B cells. Furthermore, classification of these patients revealed different probable pathophysiological mechanism of their disease, suggesting a heterogenous population of PAD patients attended in southwestern Colombia. However, the numbers of PAD participants included in this study is not optimal for statistical analysis due to the high complexity and heterogeneity of PAD disorders, therefore, studies with more patients are needed. But more importantly, this study not only highly the importance of B cell subsets analysis in PAD patients, which are currently understudied in Colombia, but also in non-PAD patients with bronchiectasis and recurrent pneumonia.

\section{Declarations}




\section{Acknowledgments}

The authors would like to acknowledge Dr. Maximiliano Parra, Dr. Luis Fernando Guerrero, Dr. Ricardo Mosquera, Dr. Omar Sierra for their contribution in patients' identification and Hospital Universitario del Valle "Evaristo Garcia" wich facilitated the use of Flow cytometry core facility.

\section{Funding}

This study was funded by Takeda Pharmaceuticals International AG Singapore Branch, grant number IIR-BXT-COL-001923.

\section{Conflicts of interest}

The authors declare that they have no conflict of interest.

\section{Availability of data and material}

All data used to support the findings are included in the article and are available from the corresponding author upon request.

\section{Code availability}

Not applicable

\section{Author contributions}

All authors contributed to the study conception and design. Material preparation, data collection and analysis were performed by Giraldo-Ocampo Sebastian, Zea-Vera Andrés F and Bonelo Perdomo Anilza. The first draft of the manuscript was written by Giraldo-Ocampo Sebastian and all authors commented on previous versions of the manuscript. All authors read and approved the final manuscript.

\section{Ethics approval}

The study was approved by the Institutional committee of Human Ethical review of the Universidad del Valle, ID: 010-019R and by the ethics committee of Hospital Universitario del Valle "Evaristo Garcia”, ID: 050-2019.

\section{Consent to participate}

Informed consent was obtained from all individual participants included in the study. Informed consent was obtained from legal guardians and the participant in case of individuals under the age of 18 .

\section{Consent for publication}

Not applicable

\section{References}

1. Modell V, Orange JS, Quinn J, Modell F. Global report on primary immunodeficiencies: 2018 update from the Jeffrey Modell Centers Network on disease classification, regional trends, treatment modalities, and physician reported outcomes. Immunol Res. 2018;66:367-80.

2. Bousfiha A, Jeddane L, Picard C, et al. Human Inborn Errors of Immunity: 2019 Update of the IUIS Phenotypical Classification. J Clin Immunol. 2020;40:66-81.

3. Tangye SG, Al-herz W, Bousfiha A, Chatila T, Cunningham-rundles C. Human Inborn Errors of Immunity: 2019 Update on the Classification from the International. Union of Immunological Societies Expert Committee; 2020.

4. Durandy A, Kracker S, Fischer A. Primary antibody deficiencies. Nat Rev Immunol. 2013;13:519-33.

5. Baumann U, Routes JM, Soler-Palacín P, Jolles S. The lung in primary immunodeficiencies: New concepts in infection and inflammation. Front Immunol; 2018.

6. Ramzi N, Jamee M, Bakhtiyari M, et al. Bronchiectasis in common variable immunodeficiency: A systematic review and meta-analysis. Pediatr Pulmonol. 2020;55:292-9.

7. Chalmers JD, Chang AB, Chotirmall SH, Dhar R, McShane PJ. Bronchiectasis. Nat Rev Dis Prim; 2018.

8. ESID Registry Working Party. (2019) ESID Registry - Working definitions for clinical diagnosis of IEI. 1-33.

9. Al Kindi M, Mundy J, Sullivan T, Smith W, Kette F, Smith A, Heddle R, Hissaria P. Utility of peripheral blood B cell subsets analysis in common variable immunodeficiency. Clin Exp Immunol. 2012;167:275-81.

10. Warnatz K, Denz A, Dräger R, Braun M, Groth C, Wolff-Vorbeck G, Eibel H, Schlesier M, Peter HH. Severe deficiency of switched memory B cells (CD27+lgMIgD-) in subgroups of patients with common variable immunodeficiency: A new approach to classify a heterogeneous disease. Blood. 2002;99:1544-51.

11. Piqueras B, Lavenu-Bombled C, Galicier L, Bergeron-Van Der Cruyssen F, Mouthon L, Chevret S, Debré P, Schmitt C, Oksenhendler E. Common variable immunodeficiency patient classification based on impaired B cell memory differentiation correlates with clinical aspects. J Clin Immunol. 2003;23:385400.

12. Wehr C, Kivioja T, Schmitt C, et al. The EUROclass trial: Defining subgroups in common variable immunodeficiency. Blood. 2008;111:77-85. 
13. Driessen GJ, Van Zelm MC, Van Hagen PM, et al. B-cell replication history and somatic hypermutation status identify distinct pathophysiologic backgrounds in common variable immunodeficiency. Blood. 2011;118:6814-23.

14. Vélez AC, Castaño DM, Gómez RD, Orrego JC, Moncada M, Franco JL. Inmunodeficiencia común variable: caracterización clínica e inmunológica de pacientese identificación de subgrupos homogéneoscon base en la tipificación de subpoblaciones de linfocitos B. Biomédica. 2015;35:101-16.

15. Pasteur MC, Bilton D, Hill AT. (2010) British thoracic society guideline for non-CF bronchiectasis. Thorax.

16. Kaplan KA, Beierle EA, Faro A, Eskin TA, Flotte TR. Recurrent pneumonia in children: A case report and approach to diagnosis. Clin Pediatr (Phila). 2006;45:15-22.

17. Dongen JJM, Van, Burg M, Van Der, Kalina T. (2019) EuroFlow-Based Flowcytometric Diagnostic Screening and Classification of Primary Immunodeficiencies of the Lymphoid System. 10:1-21.

18. Bateman EAL, Ayers L, Sadler R, et al. T cell phenotypes in patients with common variable immunodeficiency disorders: Associations with clinical phenotypes in comparison with other groups with recurrent infections. Clin Exp Immunol. 2012;170:202-11.

19. Wong GK, Huissoon AP. T-cell abnormalities in common variable immunodeficiency: The hidden defect. J Clin Pathol. 2016;69:672-6.

20. Celiksoy MH, Yildiran A. A comparison of B cell subsets in primary immune deficiencies that progress with antibody deficiency and age-matched healthy children. Allergol Immunopathol (Madr). 2016;44:331-40.

21. Carsetti R, Rosado MM, Donnanno S, Guazzi V, Soresina A, Meini A, Plebani A, Aiuti F, Quinti I. The loss of IgM memory B cells correlates with clinical disease in common variable immunodeficiency. J Allergy Clin Immunol. 2005;115:412-7.

22. Lee J, Kuchen S, Fischer R, Chang S, Lipsky PE. Identification and Characterization of a Human CD5 + Pre-Naive B Cell Population. J Immunol. 2009;182:4116-26.

23. Stuchlý J, Kanderová V, Vlková M, et al. Common Variable Immunodeficiency patients with a phenotypic profile of immunosenescence present with thrombocytopenia. Sci Rep. 2017;7:1-13.

24. King PT, Hutchinson P, Holmes PW, Freezer NJ, Bennett-Wood V, Robins-Browne R, Holdsworth SR. Assessing immune function in adult bronchiectasis. Clin Exp Immunol. 2006;144:440-6.

\section{Figures}
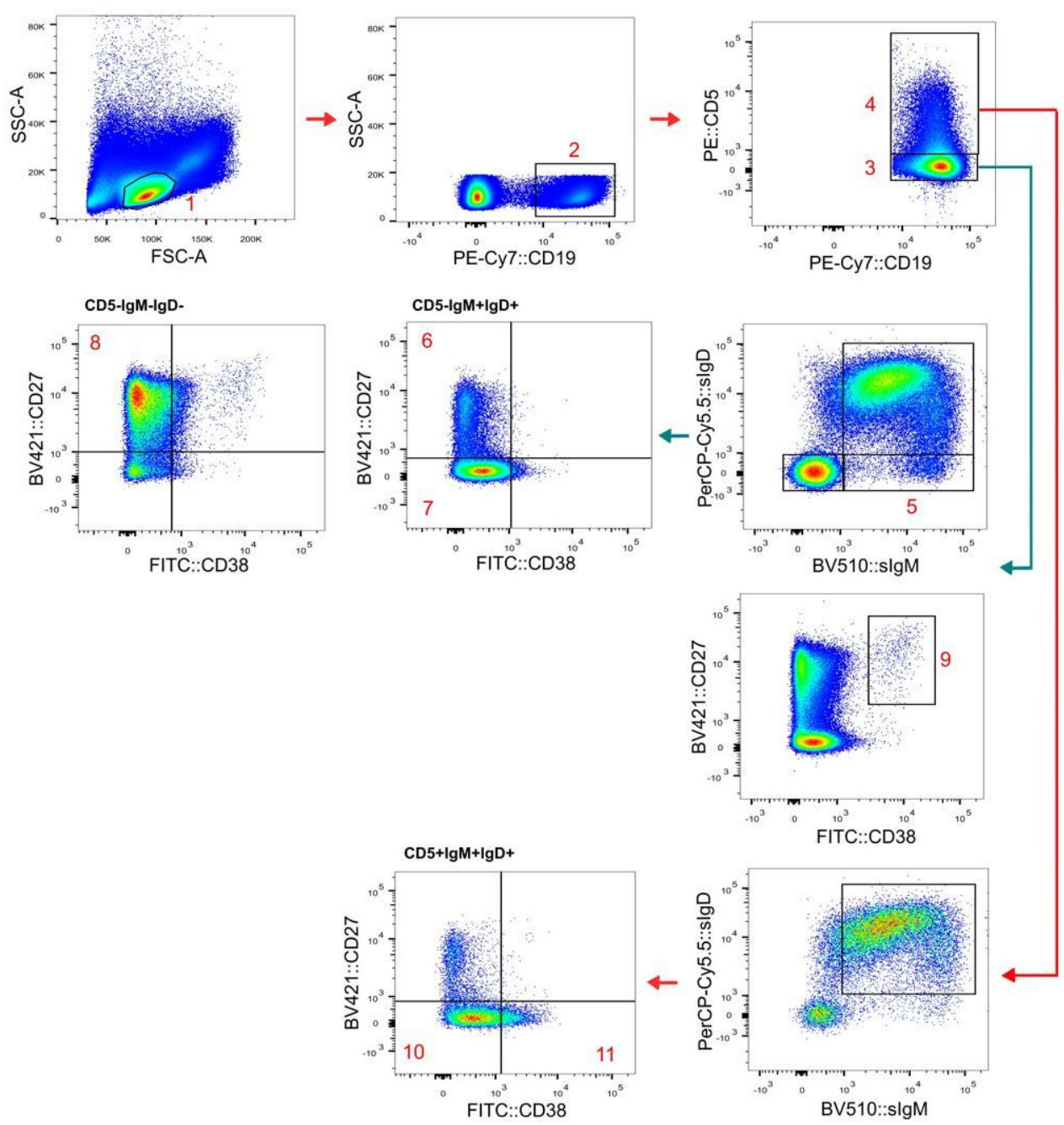

Page 9/12 
Figure 1

Gating strategy for the main B cell subsets identification. Doublets were excluded (not shown). 1. Lymphocytes, 2. B cells, 3. CD5- B cells, 4. CD5+ B cells, 5. IgM only memory cells (Positive for CD27, not shown), 6. Unswitched memory B cells. 7. Naïve CD5- B cells, 8. Switched memory B cells, 9. Plasmablasts, 10. Naïve CD5+ B cells, 11. Transitional B cells

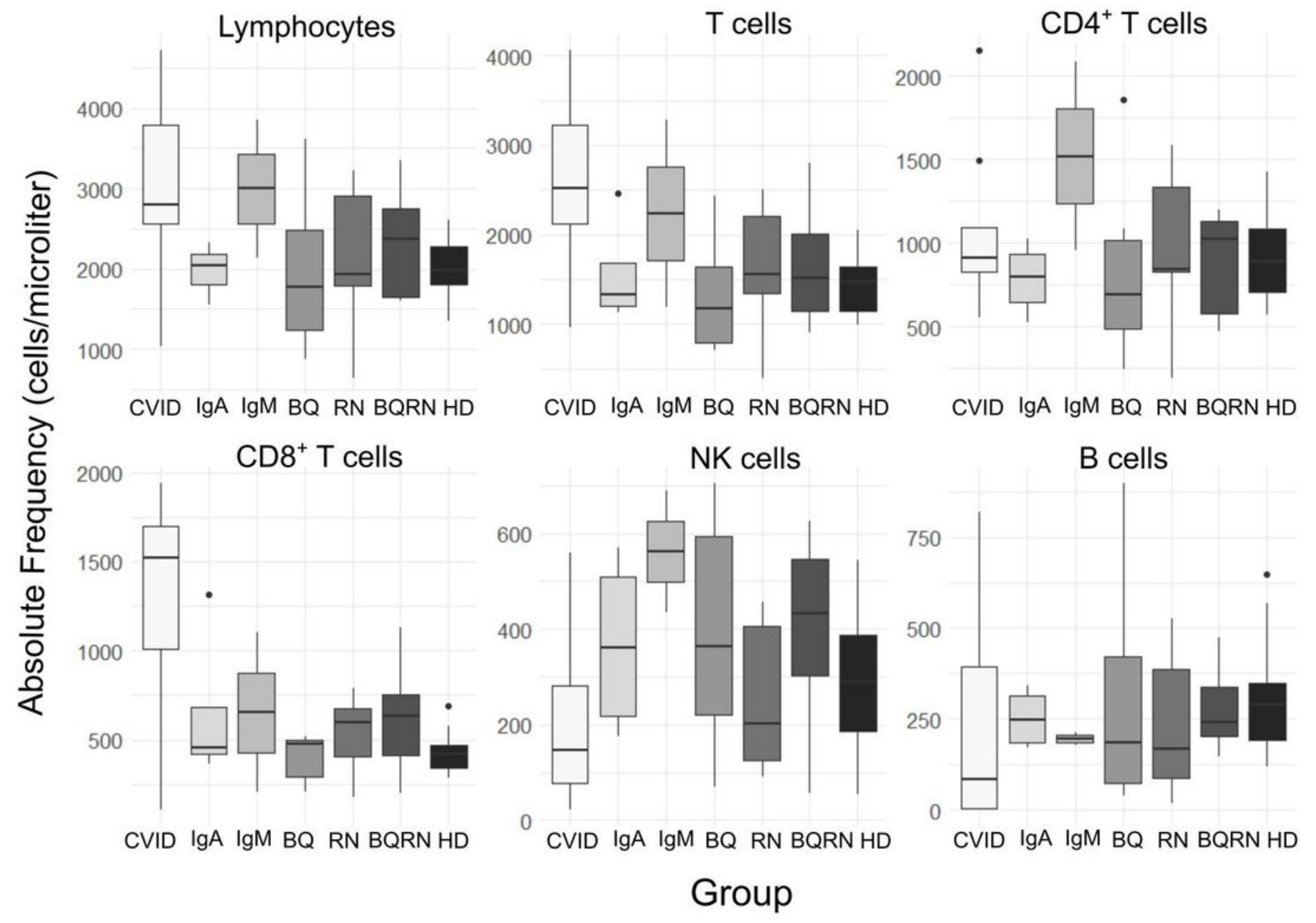

Figure 2

Absolute frequency of blood lymphocyte populations. Absolute frequency is expressed as cells per microliter of blood. IgA refers to SIgAD and IgM to SIgMD participants 

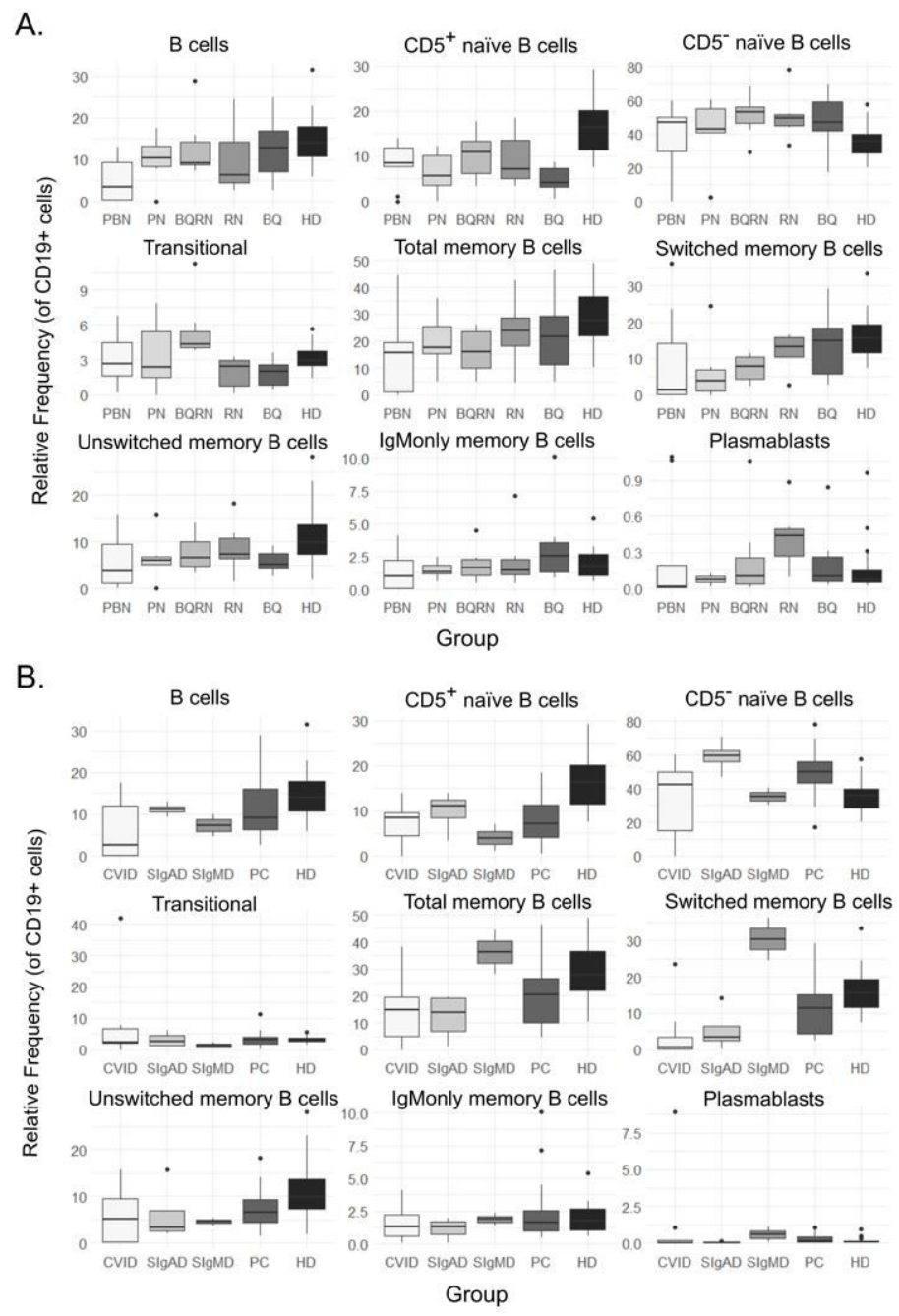

\section{Figure 3}

Frequency of B cell subsets as percentage of B (CD19+) cells. PBN: patients with PAD, bronchiectasis and recurrent pneumonia. PC: any pulmonary complication. PN: PAD patients with recurrent pneumonia. Extreme data points were removed for visualization purpose (one data in CVID transitional B cells and one in CVID plasmablasts) 


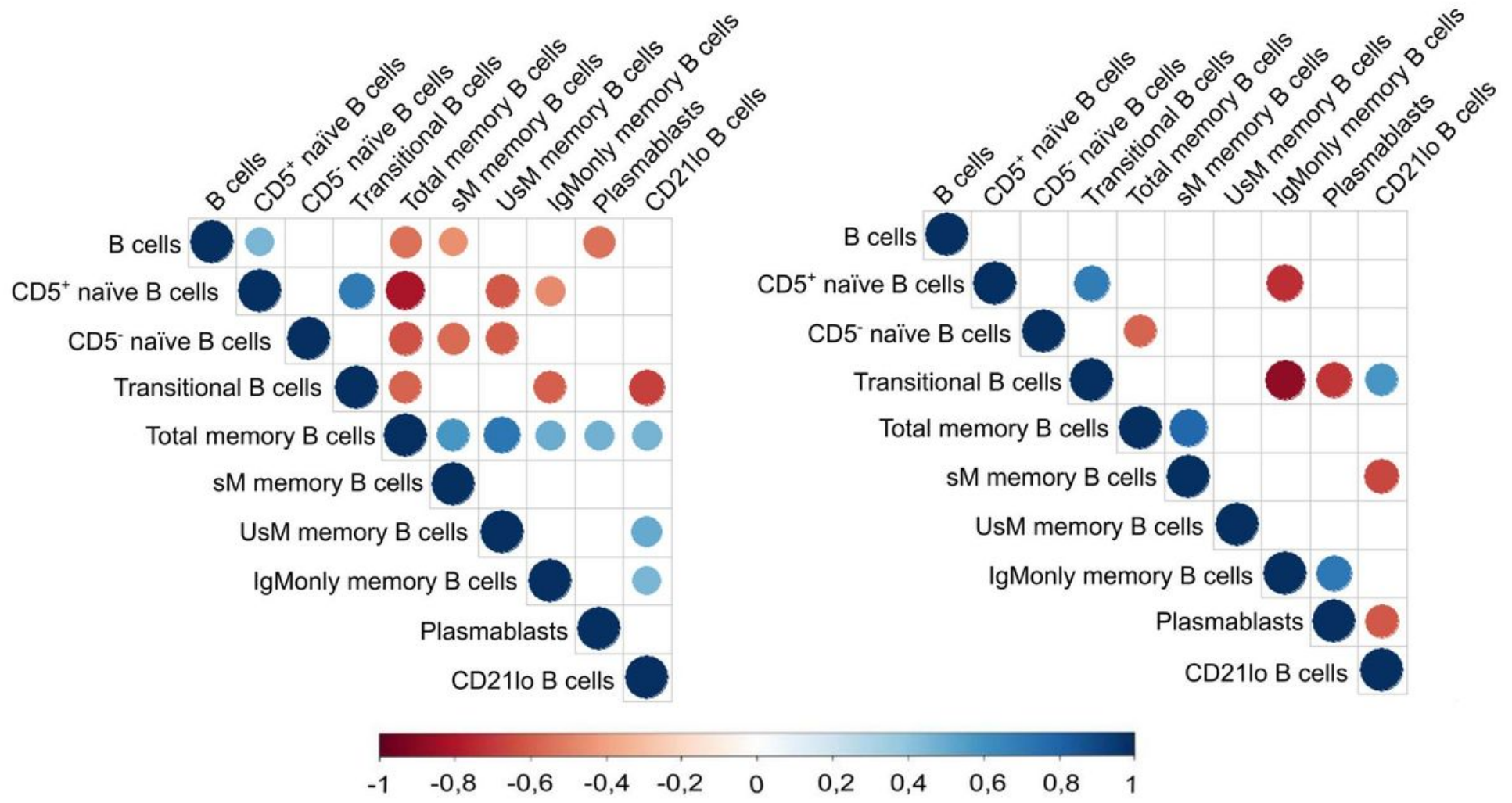

Figure 4

Correlogram of $B$ cell subsets in (a) healthy donor, $n=20$ and (b) participants with $P A D, n=12$. Subjects with relative frequency of $B$ cells less than $1 \%$ were excluded from analysis. $B$ cell subsets are expressed as percentage of B cells. Only spearman coefficients with $p<0.05$ are shown 